\title{
SEMEADURA DO HÍBRIDO LYRA DE MAMONA (Ricinus communis L.) SOB PLANTIO DIRETO
}

\author{
Seeding of castor bean (Ricinus communis L.) hybrid Lyra in no-tillage system
}

\author{
Nilza Patrícia Ramos ${ }^{1}$, Juliana Altafin Galli ${ }^{2}$, Edson Perito Amorim ${ }^{3}$, \\ Marcos Roberto da Silva ${ }^{4}$, Antonio Lúcio Mello Martins²
}

\begin{abstract}
RESUMO
A semeadura mecanizada da mamona (Ricinus communis L.) pode reduzir o tempo de operação e os custos associados à mãode-obra, porém a escassez de informações nesta área tem prejudicado a adoção correta desta tecnologia. Assim, objetivou-se com esse trabalho verificar a regularidade da distribuição longitudinal de sementes do híbrido Lyra de mamona, em área de plantio direto e sua relação com rendimento de grãos; bem como a viabilidade da aplicação de cartas de controle para a avaliação do processo de semeadura, nesta cultura. O ensaio foi conduzido em área comercial de produção de grãos de mamona sob plantio direto, sendo avaliadas: distribuição longitudinal, porcentagens de espaçamentos normais, falhos e duplos na linha, número de planta por metro linear, altura de plantas, altura e comprimento do racemo primário e rendimento de grãos. Utilizou-se a estatística descritiva, a análise de correlações e as cartas de controle para a avaliação dos parâmetros propostos. Há necessidade de refinamento nas regulagens de semeadoras-adubadoras de precisão para a semeadura do híbrido Lyra de mamona, em áreas de plantio direto; a distribuição longitudinal de sementes de mamona influencia vários parâmetros fitotécnicos, incluindo o rendimento de grãos; a aplicação da carta de controle é uma ferramenta eficiente para a avaliação do processo de semeadura da mamona.
\end{abstract}

Termos para indexação: Semeadura, plantio direto, cartas de controle, Ricinus communis.

\section{ABSTRACT}

The mechanized sowing of castor bean (Ricinus communis L.) can reduce the operation time and the costs associated to labor, however the privation of information in this area have damaged the correct adoption of this technology. Thus, the research had as an aim to verify the regularity of longitudinal distribution of hybrid Lyra_castor bean seeds, in a no-tillage system area, and its relationship with yield; and the viability of control charts for evaluation of sowing in this crop. The essay was carded out in a commercial area of grain production in no-tillage system. one evaluated: longitudinal distribution, percentage of normal, defective and double spaces in line, number of plants per linear meter, height of plants, height and length of primer raceme and yield. For the evaluation of the proposed parameters, one used the describable statistic, the correlation analysis and control charts. The results allowed to conclude that it is necessary to enhance the regulation of seeder-fertilizer for mechanized sowing of castor bean hybrid Lyra, in no-tillage system areas. The longitudinal distribution of castor bean affect seeds grain yield and other phytotechnic parameters and the control charts are efficient to evaluate the mechanized castor bean sowing.

Index terms: Sowing, no-tillage, control charts, Ricinus communis.

\section{(Recebido em 13 de novembro de 2006 e aprovado em 30 de outubro de 2007)}

\section{INTRODUÇÃO}

A cultura da mamona (Ricinus communis L.), no Brasil, caracteriza-se historicamente pelo cultivo em áreas de baixo nível tecnológico, onde se inclui a semeadura manual, em covas, com espaçamentos largos e posterior operação de desbaste acarretando, muitas vezes, incrementos significativos nos custos de produção pelo uso intensivo de mão-de-obra (SANTOS et al., 2001; SAVY
FILHO, 2005). Este panorama vem se modificando com os avanços tecnológicos alcançados dentro desta cadeia produtiva, pela colaboração de técnicos de extensão e pesquisa, e do maior interesse de exploração em grandes áreas.

Como regra geral, na produção de grãos, a operação de semeadura é considerada um dos processos mais relevantes (SILVA \& DANIEL, 2004), pois deve assegurar a dosagem recomendada de sementes por área, o

\footnotetext{
'Engenheira Agrônoma, Doutora, Pesquisadora - Embrapa Meio Ambiente/CNPMA - Rodovia SP 340, Km 127,5 - Cx. P. 69 - 13820-000 - Jaguariúna, SP-npramos@cnpma.embrapa.br

2Engenheiros Agrônomos, Doutores, Pesquisadores - Pólo Regional de Desenvolvimento Tecnológico dos Agronegócios/PRDTA - Agência Paulista de Tecnologia dos Agronegócios/APTA - Rodovia Washington Luiz, Km 372 - Cx. P.24 - 15830-000 - Pindorama, SP - julianagalli@aptaregional.sp.gov.br: Imartins@apta.sp.gov.br - Bolsista CNPq

${ }^{3}$ Engenheiro Agrônomo, Doutor, Pesquisador - Departamento de Melhoramento Vegetal - Embrapa Mandioca e Fruticultura Tropical/CNPMF- Rua Embrapa, s/n $/ n^{\circ}$ 44380-000 - Cruz das Almas, BA - edson@cnpmf.embrapa.br

${ }^{4}$ Engenheiro Agrícola, Mestre, Professor Assistente - Centro de Ciências Exatas e Tecnológicas/CETEC - Universidade Federal do Recôncavo Baiano/ UFRB - Campus de Cruz das Almas - Cx. P. 082 - 40380-000 - mrsilva@ufrb.br
} 
acondicionamento na profundidade desejada e a distribuição uniforme das sementes ao longo da linha. Neste contexto, a mecanização desta operação visa, principalmente, maior eficiência e rapidez, além do conforto oferecido ao operador, potencializando o trabalho individual e o rendimento (SILVEIRA et al., 2005).

Kurachi et al. (1986) relataram que as semeadorasadubadoras, de diferentes tipos e modelos existentes no mercado brasileiro, devem ter sua eficiência avaliada por meio de dois parâmetros principais com relação à distribuição longitudinal de sementes, sendo eles, a porcentagem de espaçamentos aceitáveis e o coeficiente de variação geral dos espaçamentos aceitáveis. A uniformidade de distribuição longitudinal de sementes foi apontada entre as que mais contribuem para um estande adequado de plantas de milho e para a melhoria do seu rendimento (KURACHI et al., 1989).

Os requisitos de regularidade da distribuição longitudinal de sementes para semeadoras devem estar de acordo com o mecanismo dosador empregado. Coelho et al. (1992) afirmam que os valores mínimos aceitáveis de espaçamento e máximos coeficientes de variação admissíveis para o mecanismo do tipo pneumático são $90 \%$ e $30 \%$, respectivamente. Entretanto, esses limites de tolerância podem se alterar, em função da cultura, pois a mamona, por exemplo, pode ter valores mínimos aceitáveis de espaçamento de até $80 \%$, pela dificuldade de distribuição de sementes, em função da classificação dos lotes em um pequeno número de peneiras e do cultivo em espaçamentos largos $(0,90$ e $1,00 \mathrm{~m})$, que desfavorecem a uniformidade da distribuição de sementes pelas máquinas.

A verificação da qualidade de processos pode ser feita pelo controle estatístico de processo (CEP) que auxilia a detecção rápida de variações não-aleatórias envolvendo o uso de técnicas estatísticas (MONTGOMERY, 1997). Também, a carta de controle é uma técnica primária do CEP utilizada no monitoramento do mesmo, pois reflete a variabilidade existente no sistema. Entre as vantagens citadas para seu uso destacam-se: identificação de desvios resultantes de causas especiais, tornando o processo previsível em termos de atender ou não as especificações desejadas, e determinação da necessidade de alterações quando necessário (ANTUNES \& ENGEL, 1999).

$\mathrm{O}$ uso das cartas de controle foi eficiente para verificar a qualidade do processo de distribuição longitudinal de sementes de girassol, em ensaios conduzidos por Lino et al. (2003) trabalhando em bancadas de laboratório, e Silva et al. (2005), trabalhando com avaliações em campos comerciais, quando se conclui que sua aplicação permite a comparação imediata com os limites de especificação do processo e possibilita a análise de desempenho, facilitando correções. Assim, as cartas são ferramentas que permitem análises rápidas e objetivas da operação de semeadura, podendo muitas vezes substituir a análise estatística convencional, que é mais demorada e laboriosa.

Como contribuição para esclarecimentos tecnológicos na cadeia produtiva da mamona, objetivouse com este trabalho verificar a regularidade da distribuição longitudinal de sementes do híbrido Lyra de mamona, em área de plantio direto e sua relação com o rendimento de grãos, bem como a viabilidade da aplicação da carta de controle como ferramenta de avaliação e melhoria do processo de semeadura dessa cultura.

\section{MATERIAL E MÉTODOS}

O ensaio foi realizado em área de produção comercial de mamona do Pólo Regional de Desenvolvimento Tecnológico dos Agronegócios Centro Norte, localizado em Pindorama-SP, durante o período de "safrinha" (fevereiro a julho), em 2006. O solo da região é classificado como Argissolo eutrófico A moderado, textura arenosa/ média, Unidade Pindorama, e o clima caracteriza-se pela temperatura média anual de $22,8^{\circ} \mathrm{C}$, precipitação média anual de 1.390,3 mm com altitudes variando de 498 a 594m.

Como material vegetal utilizou-se um lote comercial de sementes do híbrido Lyra de mamona; semeado em 24/ 02/2006 em sistema plantio direto, o qual já estava implantado na área há três anos. Anteriormente, esta mesma área foi ocupada com um campo de produção de sementes de mamona, semeado em janeiro de 2005 e colhido de maneira parcelada de junho até outubro deste referido ano. Após a colheita os restos culturais permaneceram na área, sendo roçados no mês de dezembro, para a melhor distribuição de massa seca sobre a superfície do solo. Aproximadamente 20 dias antes da semeadura, aplicou-se glifosate $\left(4 \mathrm{~L} \mathrm{ha}^{-1}\right)$ e $2,4 \mathrm{D}\left(2 \mathrm{~L} \mathrm{ha}^{-1}\right)$ para eliminação das plantas remanescentes de mamona e outras infestantes.

A operação de semeadura foi feita com uma semeadora-adubadora de precisão, marca Jumil, modelo 2600SH para plantio direto, com dosador de sementes do tipo pneumático e quatro unidades de semeadura espaçadas em $90 \mathrm{~cm}$; a velocidade de deslocamento do conjunto trator-semeadora foi de $6 \mathrm{~km} \mathrm{~h}^{-1}$. O disco de semeadura foi utilizado na recomendação de 1,25 plantas de mamona por metro linear.

No ponto de colheita da cultura, foram avaliados os parâmetros: distribuição longitudinal de sementes (DLS), em centímetros; porcentagem de espaçamentos aceitáveis (EN), falhos (EF) e duplos (ED) na linha 
(KURACHI et al., 1989); número de plantas por metro linear $\left(\mathrm{Pl} \mathrm{m}{ }^{-1}\right)$; altura de plantas (AP), altura de inserção (IR) e comprimento do racemo primário (CR) em centímetros, além de rendimento de grãos (REND) em kg ha ${ }^{-1}$. As amostras foram retiradas em cinco metros lineares de cada uma das linhas de semeadura, em 20 pontos da área de produção, eqüidistantes entre si.

Utilizou-se a estatística descritiva para análise dos dados, além das correlações de Pearson; sendo a distribuição longitudinal de sementes também avaliada por carta de controle (LINO et al., 2003). A partir da recomendação de 1,25 plantas por metro linear, os limites de controle da distribuição longitudinal foram estipulados, tendo como ponto de referência central ( $x$ ref.) $80 \mathrm{~cm}$.

A denominação das classes foi proposta para girassol por Ungaro et al. (1999), enquanto os intervalos foram adaptados para a mamona a partir de intervalos anteriores propostos por Casão Júnior \& Siqueira (2003). Sendo consideradas as faixas: "inaceitável abaixo do ideal" as distâncias entre plantas <64 cm; "aceitável abaixo do ideal" entre $65-71 \mathrm{~cm}$; “ideal” entre 72-88 cm; "aceitável acima do ideal" entre $89-96 \mathrm{~cm}$ e "inaceitável alto" $>97 \mathrm{~cm}$.

Tanto a análise descritiva, quanto às estimativas das correlações de Pearson entre as características foram obtidas utilizando-se o pacote estatístico computacional SAS v. 8.1 (SAS INSTITUTE, 2000).

\section{RESULTADOS E DISCUSSÃO}

Com base na estatística descritiva (Tabela 1), observou-se que os coeficientes de variação para a maioria dos caracteres relacionados ao processo de semeadura encontravam-se elevados, sendo que para a distribuição longitudinal de sementes (DLS) o valor foi de 50,92\%, bastante superior ao limite estabelecido por Coelho et al. (1992) para semeadoras pneumáticas, que foi de $30 \%$. Este valor elevado sugere problemas graves na operação de semeadura, envolvendo a desuniformidade na distribuição de sementes na linha de semeadura, aspectos relacionados ao acondicionamento dessas sementes em profundidade inadequada e com a pressão exercida pelo mecanismo compactador do sulco.

A média de DLS foi de $131,89 \mathrm{~cm}$, enquanto o valor de referência seria $80 \mathrm{~cm}$, indicando um desvio superior a 64 pontos percentuais, em relação ao desejado na operação; sendo classificado como ruim por Casão Júnior \& Siqueira (2003). Mesmo para a mamona, que poderia tolerar um limite de desvio superior aos $10 \%$ propostos como bons por esses autores, os valores observados não foram satisfatórios e comprovam a necessidade de maiores cuidados na semeadura dessa cultura, onde deve ser incluída a maior atenção com as regulagens de rotina e também do operador responsável pela semeadura do conjunto.

Com relação à distribuição das porcentagens de espaçamentos aceitáveis, falhos e duplos (Tabela 1) foi verificada uma grande incidência de falhas ( $\bar{x}=60,88 \%$ ), com valores máximos de até $95,83 \%$, indicando a ausência quase que total de plantas em alguns pontos analisados. Por outro lado, os valores aceitáveis variaram de 4,17 a 48,43\%, com coeficiente de variação de $44,86 \%$, o que demonstra a ineficácia do processo de semeadura na área de produção. Mahl et al. (2004) também obtiveram altos coeficientes de

Tabela 1 - Estatística descritiva da distribuição longitudinal de sementes (DLS-cm); porcentagem de espaçamentos aceitáveis (EN), falhos (EF) e duplos (ED) na linha; número de plantas por metro linear ( $\left.\mathrm{Pl} \mathrm{m} \mathrm{m}^{-1}\right)$; altura de plantas (AP - cm) e de inserção do racemo primário (IR- cm); comprimento do racemo (CR - cm) e rendimento de grãos $\left(\mathrm{REND}-\mathrm{kg} \mathrm{ha}^{-1}\right)$, avaliados em plantas do híbrido de mamona Lyra, conduzidas em sistema plantio direto. Pindorama - SP, 2006.

\begin{tabular}{lrrrrrrrrr}
\hline & DLS & \multicolumn{1}{c}{ EN } & EF & ED & Pl m $^{-1}$ & AP & IR & CR & REND \\
\hline Média & 131,89 & 28,37 & 60,88 & 12,94 & 0,82 & 85,81 & 42,07 & 34,91 & 674,61 \\
Mediana & 110,34 & 31,25 & 61,90 & 8,04 & 0,70 & 87,92 & 41,68 & 35,42 & 431,98 \\
Max & 295,00 & 48,43 & 95,83 & 42,33 & 2,10 & 100,63 & 51,25 & 41,69 & 1193,10 \\
Min & 51,35 & 4,17 & 12,50 & 0,00 & 0,25 & 70,50 & 36,50 & 26,24 & 208,89 \\
Ampl. & 343,65 & 44,26 & 83,33 & 42,33 & 1,85 & 30,13 & 14,75 & 15,45 & 984,22 \\
CV\% & 50,92 & 44,86 & 37,02 & 107,34 & 60,16 & 9,89 & 9,86 & 11,74 & 40,74 \\
DP & 67,15 & 12,72 & 22,54 & 13,89 & 0,49 & 4,15 & 6,50 & 4,10 & 273,55 \\
\hline
\end{tabular}

Max - valor máximo observado; Min - valor mínimo observado; Ampl - amplitude de variação; CV\% - coeficiente de variação experimental em porcentagem; DP- desvio padrão. 
variação para a porcentagem de espaçamentos falhos e duplos na cultura do milho, ao contrário de Branquinho et al. (2004), trabalhando com soja, não observaram altos valores no coeficiente de variação para esses parâmetros, mas concluíram que menos da metade das sementes foram depositadas em espaçamentos aceitáveis $(=44,80 \%)$, independente do manejo de solo adotado e da velocidade da operação.

Talvez, a maior quantidade de falhas se deva ao cultivo com espaçamentos maiores entre as plantas, na linha, e às características físicas e fisiológicas (mais pesadas, de tamanho grande e vigor reduzido) das sementes de mamona que reduzem as possibilidades de deposição duplas de sementes em comparação à maioria das culturas graníferas, semeadas mecanicamente. Lembrando que a distribuição e o nível de danificação das sementes dependem, principalmente, da forma, do tamanho e da uniformidade no tamanho das sementes (ROCHA et al., 1998).

Também a necessidade de treinamento e maior intimidade dos técnicos com a cultura da mamona pode ter interferido na qualidade da operação, neste sentido Santos (2005), trabalhando com qualidade na avaliação do processo de pulverização de defensivos, demonstrou claramente a interferência do fator mão-de-obra na qualidade do processo e da necessidade de qualificação profissional.

Quando se comparou a elevada porcentagem de falhas com o rendimento de grãos, observou-se efeito altamente negativo, com variação de mais de $85 \%$ entre o valor mínimo e máximo obtidos, (208,89 e 1193,10 kg ha-1, respectivamente). Esta observação se confirma na Tabela 2, onde o rendimento de grãos (REND) e DLS são inversamente correlacionados, com alto nível de significância, como já era esperado, pois com o aumento das DLS tem-se menor número de plantas por área, o que reduz rendimento de grãos. Assim, a redução de $34,4 \%$ no número de plantas por metro linear $\left(\mathrm{PL} \mathrm{m}{ }^{-1}\right)$ (Tabela 1$)$ em relação ao valor desejado $(1,25$

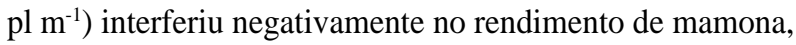
notando-se também correlação positiva e altamente significativa entre esses fatores (Tabela 2).

O híbrido Lyra de mamona, pelo seu porte baixo possui uma tendência de cultivo mais adensado, principalmente no período de safrinha, que implica em menor disponibilidade de chuvas, o que confirma a alta correlação de 0,91 observada entre PL m ${ }^{-1}$ e REND (Tabela 2). Neste caso, foram observadas populações variando de 2.780 a $23.333 \mathrm{pl} \mathrm{ha}^{-1}$, explicando os $85 \%$ de variação no rendimento de grãos. Assim, estudos de populações superiores a $20.000 \mathrm{pl} \mathrm{ha}^{-1}$ são interessantes para recomendações deste híbrido para cultivo em "safrinha" na região estudada.

Várias outras correlações significativas entre os parâmetros analisados foram encontradas (Tabela 2), onde REND só não se correlacionou com altura de plantas (AP) e comprimento do racemos (CR). A correlação entre AP e REND varia com a espécie vegetal, sendo que no caso do híbrido Lyra de mamona, que possui caracteristicamente apenas o racemo primário e algumas vezes os secundários contribuindo para o valor final de altura, esperava-se encontrar

Tabela 2 - Correlações de Pearson e suas significâncias para os parâmetros: distribuição longitudinal de sementes (DLS); porcentagem de espaçamentos aceitáveis (EN), falhos (EF) e duplos (ED) na linha; número de plantas por metro linear (Pl m $\left.\mathrm{m}^{-1}\right)$; altura de plantas (AP) e de inserção do primeiro racemo (IR); comprimento do racemo (CR) e rendimento de grãos (REND); avaliados em plantas do híbrido de mamona Lyra, conduzidas em sistema plantio direto. PindoramaSP, 2006.

\begin{tabular}{|c|c|c|c|c|c|c|c|c|c|}
\hline & DLS & EN & $\mathrm{EF}$ & ED & $\mathrm{Pl} \mathrm{m}{ }^{-1}$ & $\mathrm{AP}$ & IR & $\mathrm{CR}$ & REND \\
\hline DLS & - & $-0,59 * *$ & $-0,92 * *$ & $-0,66^{* *}$ & $-0,58 * *$ & $-0,08^{\text {n.s. }}$ & $-0,40^{\text {n.s. }}$ & $-0,04^{\text {n.s. }}$ & $-0,71 * *$ \\
\hline $\mathrm{EN}$ & & - & $-0,88 * *$ & $0,54 * *$ & $0,70 * *$ & $0,17^{\mathrm{n} . \mathrm{s}}$ & $0,48^{*}$ & $-0,01^{\text {n.s. }}$ & $0,66^{* *}$ \\
\hline $\mathrm{EF}$ & & & - & $-0,85^{* *}$ & $-0,92 * *$ & $0,05^{\text {n.s. }}$ & $-0,55^{*}$ & $0,10^{\text {n.s. }}$ & $-0,89 * *$ \\
\hline ED & & & & - & $0,88 * *$ & $-0,26^{\text {n.s. }}$ & $0,56^{*}$ & $-0,17^{\text {n.s. }}$ & $0,91 * *$ \\
\hline $\mathrm{Pl} \mathrm{m}^{-1}$ & & & & & - & $-0,28^{\text {n.s. }}$ & $0,52 *$ & $-0,30^{\text {n.s. }}$ & $0,86 * *$ \\
\hline AP & & & & & & - & $0,29^{\text {n.s. }}$ & $0,75^{* *} *$ & $-0,01^{\text {n.s. }}$ \\
\hline IR & & & & & & & - & $0,19^{\text {n.s. }}$ & $0,56^{*}$ \\
\hline $\mathrm{CR}$ & & & & & & & & - & $0,08^{\text {n.s. }}$ \\
\hline REND & & & & & & & & & - \\
\hline
\end{tabular}

\footnotetext{
${ }^{*, * * *}$ : significativo a 1 e $5 \%$ pelo teste $\mathrm{t}$, respectivamente; ${ }^{\text {ns: }}$ não significativo.
} 
correlação entre esses parâmetros. Também, não se observou a correlação entre CR e REND, talvez pela alta porcentagem de grãos chochos obtidos nesta área, em função da baixa precipitação do período $(=365 \mathrm{~mm})$, concentrando-se menos de $65 \mathrm{~mm}$ durante o enchimento de grãos.

A estatística descritiva permitiu uma análise numérica da operação de semeadura, refletindo a necessidade de melhor regulagem da máquina. Porém, esta análise não foi eficiente para verificar o comportamento pontual da distribuição de sementes ao longo da linha de semeadura, que possibilita identificar os erros na regulagem da máquina, os quais podem ser identificados pelas cartas de controle (MONTGOMERY, 1997).

As falhas de DLS de mamona ficam bem claras ao se analisar a carta de controle do processo de semeadura do híbrido Lyra (Figura 1), onde $65 \%$ dos pontos ficaram fora dos limites aceitáveis de distribuição. Deste total, 92,7 \% representaram distâncias superiores as aceitáveis, indicando falhas de distribuição, talvez pela não adequação de nível de vácuo do mecanismo pneumático, semeadura rasa, alta velocidade de deslocamento, fechamento ineficiente do sulco, entre outras possibilidades.

O fato da palhada anterior também ser de mamona, pode ter sido uma das causas de menor sucesso da semeadura mecânica, pois os restos vegetais gerados são maiores e mais fibrosos, exigindo mais dos discos de corte de palha, sendo necessária uma adequação especial no ajuste de pressão do mecanismo de corte. A maior quantidade de resíduos de raízes e caule também podem prejudicar a abertura e fechamento dos sulcos de semeadura.

$\mathrm{Na}$ literatura não foram encontrados relatos de semeadura mecânica de mamona, especialmente em áreas cultivadas anteriormente com essa mesma cultura, ficando difícil a comparação de resultados. Assim infere-se, com base nos dados levantados, que o uso da carta de controle de processos permite a visualização das variações pontuais da operação e pode auxiliar o ajuste na regulagem da distribuição de sementes, evitando prejuízos. A ferramenta demonstrou claramente a necessidade de maior refinamento na regulagem da máquina, associada ao treinamento da mão-de-obra para a o processo da semeadura, além da intensificação de pesquisas com esta cultura que esclareçam as melhores populações de plantas, em função da época de cultivo e das condições edafoclimáticas.

\section{CONCLUSÕES}

Há necessidade de refinamento e aferição nas regulagens de semeadoras-adubadoras de precisão para a semeadura mecânica do híbrido Lyra de mamona, em áreas de plantio direto.

A distribuição longitudinal de sementes de mamona influencia vários parâmetros fitotécnicos, onde se inclui o rendimento de grãos da cultura.

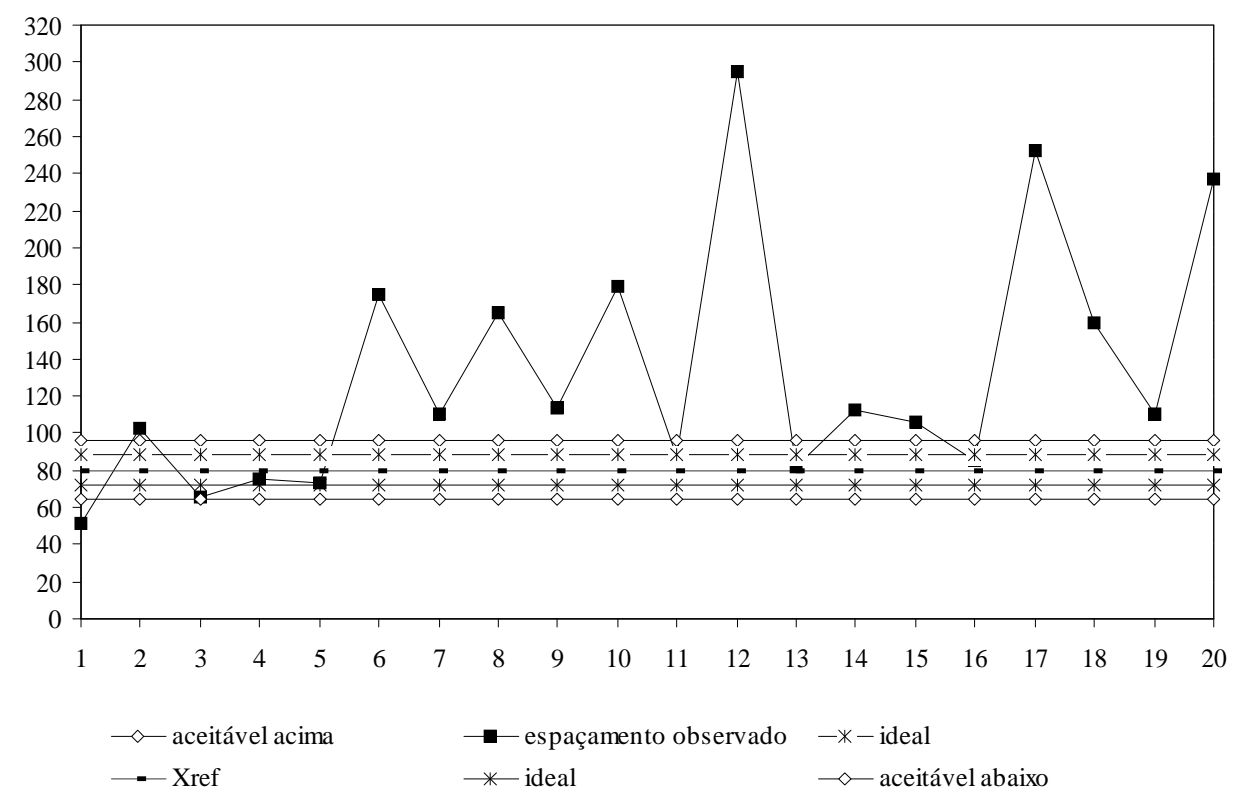

Figura 1 - Carta de controle da distribuição longitudinal de plantas, por semeadora-adubadora tipo pneumática, observada em cultivo de comercial de mamona, híbrido Lyra, no sistema plantio direto de preparo de solo. Pindorama - SP, 2006. 
A aplicação da carta de controle de processos é uma ferramenta eficiente para a avaliação da semeadura de mamona.

\section{REFERÊNCIAS BIBLIOGRÁFICAS}

ANTUNES, L. M.; ENGEL, A. Qualidade total na agropecuária. Guariba: Agropecuária, 1999, 116 p.

BRANQUINHO, K. B;; FURLANI, C. E. A.; LOPES, A.; SILVA, R. P.; GOTTA, D. C. C.; BORSATTO, E. A. Desempenho de uma semeadora-adubadora direta, em função da velocidade de deslocamento e do tipo de manejo da biomassa da cultura de cobertura do solo. Engenharia Agrícola, Jaboticabal, v. 24, n. 2, p. 374-380, 2004.

CASÃO JUNIOR, R.; SIQUEIRA, R. Resultados das avaliações do desempenho de semeadoras-adubadoras de plantio direto na Costa Oeste Paranaense. Londrina: IAPAR, 2003. $132 \mathrm{p}$.

COELHO, J. L. D.; MOLIN, J. P.; GADANHA JÚNIOR, C. D.; VASARHELYI, A. Avaliação do desempenho de máquinas aplicadoras a lanço na distribuição de gesso agrícola. In: CONGRESSO BRASILEIRO DE ENGENHARIA AGRÍCOLA, 21.; SIMPÓSIO DE ENGENHARIA AGRÍCOLA DO CONESUL, 1., 1992, Santa Maria. Anais... Santa Maria: Sociedade Brasileira de Engenharia Agrícola, 1992. p. 2058-2103.

KURACHI, S. A. H.; COSTA, J. A. S.; BERNARDI, J. A.; COELHO, J. L. D.; SILVEIRA, G. M. Avaliação tecnológica de semeadoras e/ou adubadoras: tratamento de dados de ensaio e regularidade de distribuição longitudinal de sementes. Bragantia, Campinas, v. 48, n. 2, p. 249-262, 1989.

KURACHI, S. A. H.; SILVEIRA, G. M.; COSTA, J. A.; MORAES, R. A. D. M.; BERNARDI, J. A.; MOREIRA, C. A.; PETRONI, A. C.; SILVA, J. R.; MESQUITA, C. M. Código de avaliação de semeadoras e/ou adubadoras. Campinas: IAC, 1986. 138 p.

LINO, A. C. L.; PECHE FILHO, A.; UNGARO, M. R. G.; STORINO, M. Uso de cartas de controle na avaliação do trabalho de semeadoras manuais. In: SIMPÓSIO NACIONAL DE GIRASSOL, 3.; REUNIÃO NACIONAL DE PESQUISA DE GIRASSOL, 15., 2003, Ribeirão Preto. Anais em CD-Rom. 4p. 2003.

MAHL, D; GAMERO, C. A.; BENEZ, S. H.; FURLANI, C. E. A.; SILVA, A. R. B. Demanda energética e eficiência da distribuição de sementes de milho sob variação de velocidade e condição de solo. Engenharia Agrícola, Jaboticabal, v. 24, n. 1, p. 150-157, 2004.

MONTGOMERY, D. C. Introduction to statistical quality control. New York: J. Wiley, 1997. 677 p.

ROCHA, F. E. C.; CUNHA, J. P. A. R.; FRANZ, C. A. B.; FOLLE, S. M. Avaliação de três mecanismos de distribuição de sementes. Pesquisa Agropecuária Brasileira, Brasília, v. 33, n. 3, p. 331-337, 1998.

SANTOS, S. R. Proposta metodológica utilizando ferramentas de qualidade na avaliação do processo de pulverização. 2005. 59 f. (Doutorado em Engenharia Agrícola) - UNICAMP, Campinas, 2005.

SANTOS, R. F.; BARROS, M. A. L.; MARQUES, F. M.; FIRMINO, P. T.; REQUIÃO, L. E. G. Análise econômica. In: AZEVEDO, D. M. P.; LIMA, E. F. (Ed.). O agronegócio da mamona no Brasil. Campina Grande: Embrapa Algodão, 2001. p. 17-35.

SAS Institute. SAS language and procedures: usage. Version 8.1. Cary: SAS Institute 2000. CD-ROM.

SAVY FILHO, A. Mamona tecnologia agrícola. Campinas: EMOPI, 2005. 105 p.

SILVA, M. R.; DANIEL, L.A. C. Cultivar máquinas, Pelotas: v. 3, p. 24-28, 2004.

SILVA, M. R.; UNGARO, M. R. G.; RAMOS, N. P. Qualidade da distribuição longitudinal de cinco genótipos de girassol. In: REUNIÃO NACIONAL DE PESQUISA DE GIRASSOL, 16.; SIMPÓSIO NACIONAL SOBRE A CULTURA DO GIRASSOL, 4., 2005, Londrina. Anais... Londrina: Embrapa, 2005. p. 64-67.

SILVEIRA, J. C. M.; MODOLO, A. J.; SILVA, S. L.; GABRIEL FILHO, A. Força de tração e potência de uma semeadora em duas velocidades de deslocamento e duas profundidades de deposição de sementes. Revista Brasileira de Engenharia Agrícola e Ambiental, Campina Grande, v. 9, n. 1, p. 125-128, 2005.

UNGARO, M. R. G.; PECHE FILHO, A.; LINO, A. C. L.; STORINO, M. Uso de SIG e de mapas temáticos de estande e produção de grãos na avaliação de lavoura de girassol (Helianthus Annuus L.). Engenharia Agrícola, Jaboticabal, v. 18, n. 3, p. 73-79, 1999. 